\title{
Post-pollination mechanisms and the maintenance of outcrossing in self- compatible, tristylous, Decodon verticillatus (Lythraceae)
}

\author{
CHRISTOPHER G. ECKERT* \& SPENCER C. H. BARRETT \\ Department of Botany, University of Toronto, Toronto, Ontario, Canada M5S $3 B 2$
}

\begin{abstract}
The mating systems of self-compatible plants may be vulnerable to ecological factors that influence pollen transfer. Post-pollination mechanisms may, however, buffer the mating system against ecological variation. We combined an examination of mating-system variation with experimental studies of pollen competition in a clonal, self-compatible, tristylous plant, Decodon verticillatus (Lythraceae), to assess proximate mechanisms influencing the mating system in natural populations. Outcrossing rates $(t)$ were estimated for 10 populations in a variety of habitats and exhibiting a wide range of size, density and patchiness. We also investigated whether self-compatibility results in departures from disassortative mating, by estimating morph-specific rates of outcrossing and disassortative mating $(d)$. All population-level estimates of $t$ indicated significant self-fertilization (average $\hat{t}=0.72$ ) and weak disassortative mating (average $\hat{d} \approx 0.30$ ). There were small but significant differences in outcrossing rates among style morphs, with the mid-styled morph outcrossing at a lower rate $(0.62)$ than the short-styled morph $(0.81)$ and the long-styled morph intermediate (0.71). The expectation of wide variation in $t$ among populations was not supported. Populationlevel estimates were distributed over a narrow range (0.63-0.86) with few significant differences. A possible mechanism underlying this pattern was revealed by mixed-donor pollinations. Outcross pollen experienced a substantial siring advantage over self pollen. Outcrossing in $D$. verticillatus may be maintained by both floral polymorphism and post-pollination mechanisms.
\end{abstract}

Keywords: allozymes, cryptic incompatibility, Decodon verticillatus, mating systems, self-fertilization, tristyly.

\section{Introduction}

Flowering plants possess a wide array of morphological and physiological mechanisms that influence mating patterns, particularly the amount of self-fertilization (Darwin, 1877; Bawa \& Beach, 1981; Richards, 1986). In many cosexual taxa, self-fertilization is largely avoided through physiological self-incompatibility (De Nettancourt, 1977; Lewis, 1979; Barrett, 1988). In species which lack strong incompatibility, there is more opportunity for the mating system to vary in response to a variety of environmental, demographical and genetic factors (Lloyd, 1980; Barrett \& Eckert, 1990). In particular, self-compatible, mass-

*Correspondence: Department of Biology, Queen's University, Kingston, Ontario, Canada K7L 3N6. flowering taxa may experience considerable variation in the delivery of self and outcross pollen through interactions between animal pollinators and the demographical features of populations such as their size, density and patchiness. Despite the evolutionary significance of mating systems (Stebbins, 1957; Allard, 1975; Jain, 1976; Charlesworth, 1992), few quantitative data are available to evaluate whether variation in self-fertilization commonly occurs in most self-compatible populations. Mating-system studies have often involved a relatively small number of populations (but see Harding et al., 1974; Ritland \& Ganders, 1987; Ritland, 1989, 1990a), and more extensive studies have specifically focused on species exhibiting conspicuous variation in floral traits likely to influence mating patterns (Rick et al., 1978; Schoen, 1982; Holtsford \& Ellstrand, 1989; Barrett \& Husband, 1990). 
Mating patterns in self-compatible plants may also be affected by physiological processes that occur after pollination (Marshall \& Folsom, 1991; Walsh \& Charlesworth, 1992). Post-fertilization selection against inbred zygotes may greatly alter the representation of selfed offspring among mature seed (Charlesworth \& Charlesworth, 1987). In addition, a growing body of experimental evidence suggests that 'cryptic' incompatibility occurring before fertilization may limit the amount of self-fertilization in a wide variety of taxa (e.g. Bateman, 1956; Weller \& Ornduff, 1977; Glover \& Barrett, 1986; Bowman, 1987; Casper et al., 1988; Cruzan \& Barrett, 1993). Yet, despite the potential significance of post-pollination processes to plant mating systems, only a handful of species has been studied experimentally, and in only a few cases have these investigations been combined with the measurement of mating-system parameters in natural populations.

The main goal of this study was to determine the degree of mating-system variation within and among populations of a mass-flowering, self-compatible, herbaceous plant, Decodon verticillatus (L.) Ell. (Lythraceae) and to investigate the role of post-pollination mechanisms in maintaining outcrossing. $D$. verticillatus is a clonal perennial that inhabits a variety of wetland habitats throughout east-central North America. In addition to variation in the size, density and patchiness of populations, prolific clonal propagation in this species gives rise to considerable variation in the size of individual genets (Eckert \& Barrett, 1993a). Such clonal spread is likely to enhance opportunities for geitonogamous self-fertilization. Hence, these features of the demography and life-history of $D$. verticillatus are likely to impose considerable heterogeneity in local pollen pools, with important consequences for the mating system of populations.

Another feature of $D$. verticillatus that may strongly influence patterns of mating is the species' tristylous breeding system. Heterostyly is traditionally viewed as an outcrossing mechanism since the polymorphism in style length and anther positions is usually associated with strong self- and intramorph-incompatibility (Ganders, 1979). Accordingly, matings are both outcrossed and primarily disassortative with respect to style morph (Piper et al., 1984; Barrett \& Shore, 1987; Barrett et al., 1987). Experimental pollinations of $D$. verticillatus, however, have revealed high levels of selfand intramorph-compatibility (Eckert, 1993; Ornduff, 1993; Eckert \& Barrett, 1994a). The absence of a rigid incompatibility system would be expected to make the mating system vulnerable to the kinds of ecological variation in pollen environments discussed above. Consequently, mating patterns would be anticipated to include large departures from disassortative outcrossing.
Strong incompatibility in most heterostylous taxa also overrides the potential effects of floral morphology on the mating system. In self-compatible heterostylous species, however, mating patterns may vary among floral morphs as a result of differences in the relative positions of stigmas and anthers. In particular, flowers of the mid-styled morph ( $\mathrm{M}$ morph) may be expected to experience higher levels of self-pollination than either long-styled ( $\mathrm{L}$ morph) or short-styled ( $\mathrm{S}$ morph) flowers, since the $\mathrm{M}$ stigma is positioned between short- and long-level anthers (Charlesworth, 1979; Kohn \& Barrett, 1992). Departures from disassortative mating in self-compatible populations have important evolutionary consequences for the maintenance of tristyly, since increased levels of selfand random-mating make populations more vulnerable to the stochastic loss of morphs from populations (Charlesworth, 1979; Heuch, 1980; Barrett et al., 1989; Eckert \& Barrett, 1992).

In this study, we combined statistical methods for estimating mating parameters in natural populations with an experimental analysis of post-pollination processes to address the following three questions concerning the pattern of mating-system variation in populations of self-compatible $D$. verticillatus. (1) Do outcrossing rates vary substantially among populations that vary widely in size, structure and habitat? (2) Is self-compatibility associated with large departures from disassortative mating and morph-specific differences in the rates of self-fertilization? (3) Are mating patterns influenced by post-pollination mechanisms?

\section{Materials and methods}

\section{Collection of seed families}

Samples of seed were collected during October and November of 1988 and 1990 from between 30 and 50 individual plants (ramets) per style morph in each of 12 populations located in the northern half of the species' range (Table 1). Within each population, plants were sampled at intervals of at least $4 \mathrm{~m}$ and an attempt was made to sample from each of the style morphs in an alternating fashion. The morph of fruiting plants was easily determined since stamens and often styles remain attached on at least some fruits on any given plant. Seed families collected were, therefore, a random sample stratified spatially by morph. This sampling method minimized the probability of sampling neighbouring ramets of the same clone. For each maternal plant, seeds were pooled from about 20 fruits collected from a single fruiting branch. Combining seeds from many fruits minimizes genetic correlations among offspring arising from correlated mating within 
a fruit (Clegg, 1980; Schoen \& Clegg, 1984, 1986). Once fruits were collected they were dried at room temperature for two weeks and stored at $5^{\circ} \mathrm{C}$. Seed families used to estimate levels of disassortative mating were collected in 1988; those used to estimate outcrossing rates were collected in 1990.

\section{Genetic analyses}

Outcrossing rates. Outcrossing rates were estimated for 10 populations of $D$. verticillatus, both at the population level and for each morph separately. Three trimorphic $(\mathrm{T})$ and three dimorphic $(\mathrm{D})$ populations were located in eastern Ontario (EO): EO-T3, EO-T6, EOT11, EO-D1, EO-D3, EO-D5 (all the dimorphic populations lacked the $\mathrm{M}$ morph). The remaining four populations were located on the southern half of the Michigan (MI) lower peninsula (MI-T3, MI-T7, MI-D1, MI-D2); one dimorphic population (MI-D2) lacked the $\mathrm{M}$ morph, the other (MI-D1) lacked the S morph. This sample of populations was chosen to represent a wide range of habitat types, population sizes, densities and patchiness (Table 1). Seed families were collected in the fall of 1990 .

To avoid upward biases in estimated outcrossing rates resulting from selection against inbred zygotes, seed families should be assayed electrophoretically as early as possible in the life cycle. In $D$. verticillatus, enzyme activity could only be obtained after seeds germinated. However, a pilot study indicated that germination rates could be increased by storing seeds wet and cold $\left(5^{\circ} \mathrm{C}\right)$. Accordingly, samples of 50 seeds per family were soaked for one month in individual $1.5 \mathrm{ml}$ microcentrifuge tubes filled with coarse silica sand dampened with distilled water. All seed families from a given population were sown at the same time in individual $5.7 \mathrm{~cm}$ plastic pots containing a $3: 1$ mixture of Pro-Mix (soil-less mix) and sandy loam, and set in Perma-Nest $\left.{ }^{\mathrm{N}} \mathrm{N}\right)$ trays $(37 \mathrm{~cm}$ long $\times 30 \mathrm{~cm}$ wide $\times 8.5 \mathrm{~cm}$ deep); 30 pots per tray. Throughout germination, water levels were kept at or just below the soil surface and temperatures ranged between $25^{\circ}$ and $35^{\circ} \mathrm{C}$. After germination had ceased, the number of seeds germinated in each pot was counted and 10 seedlings per family were sampled at random and scored for three polymorphic isozyme loci ( $A c p, I d h$ and $M d h$; Idh was monomorphic for the slow migrating allele in MI-D2). Electrophoretic methods are described in Eckert \& Barrett (1993a). Average germination rates showed a steady decline (from 85 per cent to 20 per cent) throughout the study but germination rate showed no correlation with estimated outcrossing rates (Eckert, 1993).

Single- and multi-locus outcrossing rates $\left(t_{\mathrm{s}}\right.$ and $t_{\mathrm{m}}$, respectively), and pollen $(p)$ and ovule $(u)$ allele frequencies (Appendix 1) were jointly estimated using the maximum likelihood method of Ritland (computer program MLT; Ritland, 1986, 1990b). S.E.s of the estimates were derived as the s.d. of 1000 bootstrap values with the progeny array as the unit of resampling.

Table 1 Ecological characteristics of Decodon verticillatus populations examined in this study. An estimate of population size $(\hat{N})$ is presented along with ecological characteristics and the parameters estimated in each population $(t=$ outcrossing rate; $d=$ rate of disassortative mating)

\begin{tabular}{|c|c|c|c|c|c|}
\hline $\begin{array}{l}\text { Population } \\
\text { code }\end{array}$ & $\hat{N}$ & Habitat type & $\begin{array}{l}\text { Plant } \\
\text { density }\end{array}$ & $\begin{array}{c}\text { Plant } \\
\text { dispersion }\end{array}$ & $\begin{array}{c}\text { Parameters } \\
\text { estimated }\end{array}$ \\
\hline \multicolumn{6}{|c|}{ Trimorphic populations } \\
\hline EO-T1 & 3000 & Linear river margin & Medium-low & Often patchy & $d$ \\
\hline EO-T3 & 2000 & Mat on lake margin & High & Even & $t$ \\
\hline EO-T6 & 1000 & Cattail marsh & Variable & Patchy & $t$ \\
\hline EO-T11 & 500 & Sphagnum bog & Medium-low & Even & $t$ \\
\hline MI-T3 & 3000 & Marshy lake margin & Medium & Patchy & $t$ \\
\hline Ml-T7 & 1000 & Linear river margin & Medium & Even & $t$ \\
\hline \multicolumn{6}{|c|}{ Dimorphic populations } \\
\hline EO-D1 & 800 & Swampy bays & Medium-low & 3 large patches & $t, d$ \\
\hline EO-D2 & 500 & Linear creek edge & Medium-low & Patchy & $d$ \\
\hline EO-D3 & 200 & Shallow bay edge & High & 3 large patches & $t, d$ \\
\hline EO-D5 & 75 & Low-lying bay shore & Medium & Even & $t$ \\
\hline MI-D2 & 500 & Dry cattail marsh & Low & Even & $t$ \\
\hline MI-D1 & 1000 & Narrow lake margin & Variable & Very patchy & $t$ \\
\hline
\end{tabular}


The aptness of the mixed-mating model was assessed by comparing observed progeny genotype ratios to those expected under random mixed-mating using contingency table analysis with two and 15 d.f. for diallelic and triallelic loci, respectively.

How morph-specific outcrossing rates should be estimated depends on whether pollen and ovule allele frequencies differ among morphs. Ideally, marker alleles should be distributed randomly with respect to style morph so that the outcrossing rate would be estimated for all morphs using common allele frequencies. However, if there is chance disequilibrium between marker and style morph alleles and some disassortative mating among morphs, the assumption of common allele frequencies would result in a downward bias in estimated outcrossing rates. Pollen allele frequencies estimated for each morph separately indicated differences of at least 0.15 in 15 of 29 populations by locus combinations and of at least 0.20 in four of these. Significant differences among morphs for at least one locus occurred in four of 10 populations. Therefore, morph-specific outcrossing rates were estimated for each population by considering each morph as a separate subpopulation. Concordance between these estimates and those obtained under a common allele frequency model was assessed for dimorphic populations using Ritland's (1990b) ML2T program, which jointly estimates $t$ for two groups of maternal parents under the assumption of common allele frequencies. Estimates obtained based on common pollen allele frequencies were not significantly different from those obtained by treating morphs as separate subpopulations (Eckert, 1993).

Differences in $\hat{t}$ among populations and morphs were assessed by pairwise comparison of bootstrap estimates. Two morphs or populations were considered to differ significantly if $100\left(1-\alpha_{\mathrm{PC}} / 2\right)$ per cent of the differences between randomly paired bootstrap estimates lay either all above or all below zero (where $\alpha_{\mathrm{PC}}$ is the type-I error rate per contrast). The experimentwise error rate $\left(\alpha_{\mathrm{EW}}\right)$ was held at 0.05 using Sidák's (1967) correction for non-orthogonal contrasts:

$\alpha_{\mathrm{PC}}=1-\left(1-\alpha_{\mathrm{EW}}\right)^{1 / C}$,

where $C$ is the number of contrasts. Overall differences among morphs and between trimorphic and dimorphic populations were assessed by comparing the distributions of the average bootstrap estimates for each morph or population type. For example, if $\hat{t}_{i j k}$ is the $k$ th of 1000 bootstrap estimates of the outcrossing rate for the $i$ th of three morphs (two in dimorphic populations) in the $j$ th of five populations, 1000 average estimates are calculated as:

$\hat{t}_{i+k}=\frac{1}{n} \sum_{j=1}^{n} \hat{t}_{i j k}$

where $n$ is the number of populations (five in this case). Again, a significant difference between two morphs, for instance the $\mathrm{L}$ and $\mathrm{M}$ morphs, was accepted if $100\left(1-\alpha_{\mathrm{PC}} / 2\right)$ per cent of the distribution of the differences between average estimates (e.g. $\hat{t}_{\mathrm{L}+k}-\hat{t}_{\mathrm{M}+k}$ ) lay either all above or all below zero.

Disassortative mating. Outcrossed matings may be either random or disassortative with respect to style morph. The disassortative fraction of outcrossed matings $(d)$ was estimated from segregation of style morphs in open-pollinated families from dimorphic populations using an approach by Ganders (1975), which was modified to incorporate an estimate of the selfing rate (Appendix 2). As in other tristylous taxa, the inheritance of style length in $D$. verticillatus is governed by two diallelic loci with complete dominance and epistasis between the loci (Eckert \& Barrett, 1993b). Segregation of style morph in these dimorphic populations, however, involved only one of the loci, with the allele coding for the $\mathrm{S}$ morph dominant to that for the $\mathrm{L}$ morph. Since the progeny arrays used to estimate the selfing rate $(s)$ were assayed at an earlier stage in the life-history than those used to estimate $d, s$ must be corrected for inbreeding depression expressed during the intervening period. In this case, $s$ was estimated at germination and $d$ was estimated at flowering after one year's growth in a glasshouse environment. Experimental studies of inbreeding depression in the same environment indicated that the relative performance of selfed versus outcrossed progeny in terms of survival from germination to the end of one year plus the probability of flowering was 0.614 (Eckert, 1993). Therefore, the estimated selfing rate was adjusted by multiplying by this value.

Segregation of style morphs in open-pollinated progenies was examined in four dimorphic populations from eastern Ontario (EO-D1, EO-D2, EO-D3 and EO-T1). Parental morph frequencies were estimated by random sampling of flowering ramets from throughout each population the summer before seed collection $(n=70-366)$. EO-T1 was actually trimorphic but with a very low frequency of the $\mathrm{M}$ morph. However, since $\mathrm{M}$ plants were restricted to a single location in this large $(\hat{N}=3000)$ population growing along a $2 \mathrm{~km}$ stretch of river, it was considered essentially dimorphic. Seed families were sampled (as above) in the fall of 1988 and sown out (as above) and grown to flowering under glasshouse conditions described in Eckert (1993). By December 1990, a total of 649 
offspring from about 28 families per morph per population (i.e. an average of three progeny per family) had flowered and were scored for style morph.

The proportion of homozygous $\mathrm{S}$ morph parents was estimated from $\mathrm{S}$ families with at least five flowering offspring. If all five offspring were $\mathrm{S}$ morph, the maternal plant was considered to be homozygous. In a population experiencing disassortative mating, this criterion will be correct 97 per cent of the time; however, the criterion becomes less reliable in populations where disassortative mating is weaker. In all, only $20 \mathrm{~S}$ families yielded five or more flowering offspring, and of these three ( 15 per cent) consisted of only S progeny. Although the exact frequency of homozygous $S$ parents may vary among populations, the small number of sufficiently large $S$ families precluded calculation of individual population estimates. Hence, 15 per cent was used as a best estimate for all populations. Sensitivity of the estimated rates of disassortative mating to assumptions concerning the frequency of homozygous $\mathrm{S}$ parents was assessed by calculating $\hat{d}$ over a range of genotypic frequencies for each population.

Observed proportions of the L morph in open-pollinated progenies were tested for significant departures from those expected under either complete random or complete disassortative mating using goodness-of-fit tests. Direct estimates of $d$ were also assessed statistically by bootstrapping the data (Manly, 1990). Ninetyfive per cent confidence intervals were derived from the distribution of 1000 bootstrap values per estimate using the progeny array as the unit of resampling. Resampling individual progeny gave similar results.

\section{Pollen competition experiment}

We tested for post-pollination siring differences among different pollen types in $D$. verticillatus using four different mixed pollinations: (1) self pollen (mid-level, long-level and mid-level pollen in the $\mathrm{L}, \mathrm{M}$, and $\mathrm{S}$ morphs, respectively) versus legitimate pollen (from either of the other two morphs); (2) self pollen versus illegitimate pollen from a different morph (betweenmorph) with both pollen types from the same anther level; (3) between-morph illegitimate pollen versus legitimate pollen with both pollen types from the same donor morph; and (4) illegitimate pollen from the same morph (within-morph) versus between-morph illegitimate pollen with both pollen types from the same anther level. The pollen types being compared were alternate homozygotes at one of two isozyme loci (Idh or $M d h$ ). Under typical heteromorphic incompatibility, siring differences favouring legitimate pollen should be observed in comparisons 1 and 3 but no differences should be observed in comparisons 2 and 4 . Self- incompatibility unrelated to heteromorphic incompatibility will produce differences in comparisons 1 and 2 but not 3 and 4 .

Homozygous parents were obtained by screening a sample of 575 open-pollinated progeny from 90 seed families sampled from one trimorphic population in eastern Ontario (EO-T6). Parental plants were grown in $10 \mathrm{~cm}$ plastic pots arranged randomly by genotype on two glasshouse benches under natural lighting. All pollinations were conducted during a three week period in June of 1991. Just before peak flowering, six recipient plants per morph were chosen. The remaining plants as well as recipients acted as pollen donors. On a given plant, each leaf node producing flowers was randomly assigned one of the four comparisons. Mixed pollinations were performed by covering one half of the recipient stigma with pollen from a single anther from one donor, and then immediately covering the other half with pollen from a single anther from the alternate donor. Given the design of this experiment, this method of pollen application was most efficient. However, because pollen types were segregated on the stigma, opportunities for competition between pollen types during germination or early tube growth may have been reduced. Recipients and donors were always from different open-pollinated families. Because slight delays in the application of pollen types may affect relative siring success, the order of application was alternated. For a given flowering node, flowers in opposite leaf axils received pollen donors in alternate orders. At least five flowers for each order of application per comparison were pollinated on each of six recipients per morph for a total of 1484 pollinations. Mature fruits were collected about two months later (fruit set $=81$ per cent), the seeds in two fruits per order per contrast per recipient were counted, and 30 seeds per fruit were sown out (as above). After germination had ceased, seedlings were counted and 10 per fruit were assayed.

For each pollen comparison, siring differences were assessed using a replicated goodness-of-fit test which decomposes the total deviation from equal siring success into components due to overall differences among pollen donors and heterogeneity in these differences among recipients (Sokal \& Rohlf, 1981). Groups of recipients exhibiting similar siring differences were identified using a simultaneous homogeneity of replicates test. The effects of morph of recipient and order of pollen application on siring differences were evaluated with categorical log-linear analysis using the maximum likelihood routine in JMP (version 2.0, SAS Institute, 1989). The morph of recipient and order of application were initially entered as main effects. Unimportant effects (i.e. $P>0.10$ ) were then elimi- 
nated using the Wald $\chi^{2}$ test, and the significance of the remaining terms was assessed using the more exact likelihood ratio test. Non-significant terms were continually dropped from the model. The likelihood ratio (LR) is derived by applying the log-linear model both with and without the effect being examined and calculating:

$$
\begin{aligned}
\mathrm{LR}= & \{(-\operatorname{LogLikelihood}[\text { with effect }] \\
& -(-\operatorname{LogLikelihood}[\text { without effect }])\} .
\end{aligned}
$$

For tests of individual terms LR is distributed as $\chi^{2}$ with 1 d.f. Differences in seed set among pollen comparisons were assessed with a partially hierarchical ANOVA using expected mean squares generated by JMP.

\section{Results}

\section{Outcrossing rates}

Population-level estimates. Multi-locus outcrossing rates $\left(t_{\mathrm{m}}\right)$ estimated at the population level (Table 2) ranged from 0.63 to 0.86 , and averaged $0.72( \pm 0.02$ S.E.). For all populations, 95 per cent confidence limits of $\hat{t}_{\mathrm{m}}$ lay below unity, indicating significant levels of self-fertilization in each population. Pairwise comparisons among trimorphic or dimorphic populations were generally not significant. The only significant contrast involved EO-T3 $\left(\hat{t}_{\mathrm{m}}=0.86\right)$ and EO-T11 $\left(\hat{t}_{\mathrm{m}}=0.63\right)$. Outcrossing rates were not correlated with population size $\left(r_{\mathrm{s}}=0.200\right)$ despite large variation among populations $(\hat{N}=75-3000)$.

Single-locus estimates of the outcrossing rate $\left(\hat{t}_{\mathrm{s}}\right)$ often showed considerable variation, since they are more sensitive than multi-locus estimates to violation of the assumptions underlying the mixed-mating model (Shaw et al., 1981; Ritland \& Jain, 1981). There were significant differences in $\hat{t}_{\mathrm{s}}$ among loci for five populations (EO-T6, EO-T11, EO-D3, EO-D5 and MI-D1). In all but one of these (EO-T11), the locus producing the most deviant estimate possessed highly skewed allele frequencies (Table 2, Appendix 1), which is expected to lead to reduced precision of $\hat{t}_{\mathrm{s}}$ (Ritland, 1986). Single-locus estimates are also expected to show a downwards bias caused by mating among related

Table 2 Single- and multi-locus estimates of the outcrossing rate $(t)$ for 10 populations of Decodon verticillatus. Standard errors (S.E.) are the s.d. of 1000 bootstrap samples per estimate. Multi-locus estimates were compared among trimorphic and dimorphic populations separately. Those not sharing a letter superscript are significantly different. Departures of the observed progeny genotype frequencies from those expected under the mixed-mating model are indicated by the $\chi^{2}$ values for each locus. Those marked with an asterisk are significant at the 5 per cent level. Number of families/number of progeny sampled appear in

\begin{tabular}{|c|c|c|c|c|c|}
\hline \multirow[b]{2}{*}{ Population } & \multirow[b]{2}{*}{ Locus $\dagger$} & \multirow[b]{2}{*}{$\hat{t} \pm$ S.E. } & \multicolumn{3}{|c|}{ Fit to model $\left(\chi^{2}\right) \ddagger$} \\
\hline & & & $M d h$ & $I d h$ & $A c p$ \\
\hline \multicolumn{6}{|c|}{ Trimorphic populations } \\
\hline \multirow{5}{*}{$\begin{array}{l}\text { EO-T3 } \\
\qquad(88 / 872)\end{array}$} & $M d h$ & $0.84 \pm 0.06$ & $19.2^{*}$ & - & - \\
\hline & $I d h$ & $0.87 \pm 0.07$ & - & 1.5 & - \\
\hline & Acp & $0.81 \pm 0.09$ & - & - & $6.3^{*}$ \\
\hline & Average & $0.86 \pm 0.05$ & & & \\
\hline & Multi-locus & ${ }^{\mathrm{a}} 0.86 \pm 0.04$ & 3.8 & 1.9 & $12.8^{*}$ \\
\hline \multirow{5}{*}{$\begin{array}{l}\text { EO-T6 } \\
\quad(80 / 799)\end{array}$} & $M d h$ & $0.56 \pm 0.06$ & $19.2^{*}$ & - & - \\
\hline & $I d h$ & $0.64 \pm 0.07$ & - & 1.5 & - \\
\hline & $A c p$ & $0.84 \pm 0.06$ & - & - & $50.9^{*}$ \\
\hline & Average & $0.69 \pm 0.05$ & & & \\
\hline & Multi-locus & ab $0.71 \pm 0.04$ & $17.6^{*}$ & 3.8 & $57.7^{*}$ \\
\hline \multirow{5}{*}{$\begin{array}{l}\text { EO-T 11 } \\
\quad(81 / 776)\end{array}$} & $M d h$ & $0.41 \pm 0.05$ & $19.2^{*}$ & - & - \\
\hline & $I d h$ & $0.66 \pm 0.08$ & - & 0.8 & - \\
\hline & $A c p$ & $0.74 \pm 0.08$ & - & - & $9.0^{*}$ \\
\hline & Average & $0.61 \pm 0.05$ & & & \\
\hline & Multi-locus & ${ }^{\mathrm{b}} 0.63 \pm 0.05$ & $12.6^{*}$ & 2.9 & $20.2^{*}$ \\
\hline
\end{tabular}
parentheses beneath the code for each population 
Table 2 Continued

\begin{tabular}{|c|c|c|c|c|c|}
\hline \multirow[b]{2}{*}{ Population } & \multirow[b]{2}{*}{ Locust } & \multirow[b]{2}{*}{$\hat{t} \pm$ S.E. } & \multicolumn{3}{|c|}{ Fit to model $\left(\chi^{2}\right) \ddagger$} \\
\hline & & & $M d h$ & $I d h$ & $A c p$ \\
\hline \multirow{5}{*}{$\begin{array}{l}\text { MI-T3 } \\
\qquad(81 / 697)\end{array}$} & $M d h$ & $0.80 \pm 0.09$ & 0.7 & - & - \\
\hline & $I d h$ & $0.58 \pm 0.08$ & - & 2.5 & - \\
\hline & $A c p$ & $0.66 \pm 0.10$ & - & - & $7.8^{*}$ \\
\hline & Average & $0.69 \pm 0.06$ & & & \\
\hline & Multi-locus & ${ }^{\mathrm{ab}} 0.71 \pm 0.06$ & 1.6 & $22.1^{*}$ & $7.6^{*}$ \\
\hline \multirow{5}{*}{$\begin{array}{l}\text { MI-T7 } \\
\qquad(83 / 742)\end{array}$} & $M d h$ & $0.47 \pm 0.11$ & 1.5 & - & - \\
\hline & $I d h$ & $0.48 \pm 0.09$ & - & $23.6^{*}$ & - \\
\hline & $A c p$ & $0.72 \pm 0.06$ & - & - & $21.3^{*}$ \\
\hline & Average§ & $0.62 \pm 0.05$ & & & \\
\hline & Multi-locus & ${ }^{\text {ab }} 0.70 \pm 0.05$ & $16.6^{*}$ & $24.3^{*}$ & $28.5^{*}$ \\
\hline \multicolumn{6}{|c|}{ Dimorphic populations } \\
\hline \multirow{5}{*}{$\begin{array}{l}\text { EO-D1 } \\
\qquad(57 / 568)\end{array}$} & $M d h$ & $0.65 \pm 0.10$ & $14.3^{*}$ & - & - \\
\hline & $I d h$ & $0.68 \pm 0.09$ & - & $6.5^{*}$ & - \\
\hline & Acp & $0.76 \pm 0.05$ & - & - & $21.1^{*}$ \\
\hline & Average & $0.71 \pm 0.05$ & & & \\
\hline & Multi-locus & ${ }^{\mathrm{A}} 0.72 \pm 0.05$ & 5.6 & 0.9 & $22.4^{*}$ \\
\hline \multirow{5}{*}{$\begin{array}{l}\text { EO-D3 } \\
\qquad(60 / 600)\end{array}$} & $M d h$ & $0.29 \pm 0.08$ & 2.0 & - & - \\
\hline & $I d h$ & $0.70 \pm 0.08$ & -- & $6.5^{*}$ & - \\
\hline & $A c p$ & $0.76 \pm 0.05$ & - & - & $21.1^{*}$ \\
\hline & Average $\S$ & $0.59 \pm 0.05$ & & & \\
\hline & Multi-locus & ${ }^{\mathrm{A}} 0.63 \pm 0.05$ & $19.6^{*}$ & 4.3 & $24.1^{*}$ \\
\hline \multirow{5}{*}{$\begin{array}{l}\text { EO-D5 } \\
\qquad(58 / 540)\end{array}$} & $M d h$ & $0.43 \pm 0.11$ & 0.5 & - & - \\
\hline & $I d h$ & $0.73 \pm 0.11$ & - & $9.4^{*}$ & - \\
\hline & $A c p$ & $0.84 \pm 0.04$ & - & - & $38.0 *$ \\
\hline & Average & $0.77 \pm 0.05$ & & & \\
\hline & Multi-locus & ${ }^{A} 0.78 \pm 0.05$ & $11.2^{*}$ & 5.8 & $44.2^{*}$ \\
\hline \multirow{4}{*}{$\begin{array}{l}\text { MI-D2 } \\
\qquad(53 / 340)\end{array}$} & $M d h$ & $0.79 \pm 0.17$ & $8.0^{*}$ & - & - \\
\hline & $A c p$ & $0.75 \pm 0.09$ & - & - & 3.0 \\
\hline & Average & $0.78 \pm 0.07$ & & & \\
\hline & Multi-locus & ${ }^{\mathrm{A}} 0.81 \pm 0.08$ & $6.4^{*}$ & - & 3.7 \\
\hline \multirow{5}{*}{$\begin{array}{l}\text { MI-D1 } \\
\qquad(58 / 511)\end{array}$} & $M d h$ & $0.58 \pm 0.10$ & $6.5^{*}$ & - & - \\
\hline & $I d h$ & $0.16 \pm 0.18$ & - & 2.5 & - \\
\hline & $A c p$ & $0.73 \pm 0.09$ & - & - & 1.8 \\
\hline & Average & $0.62 \pm 0.07$ & & & \\
\hline & Multi-locus & ${ }^{\mathrm{A}} 0.65 \pm 0.07$ & $6.2^{*}$ & $14.6^{*}$ & $7.9^{*}$ \\
\hline
\end{tabular}

†Loci were diallelic, except for Acp in MI-T7, EO-D1, EO-D3 and EO-D5, which was triallelic.

$\ddagger$ Significance of $\chi^{2}$ values was assessed with two and 15 d.f. for diallelic and triallelic loci, respectively.

§Average of the single-locus estimates was significantly lower than the multi-locus estimate.

individuals (biparental inbreeding). A slight reduction in average $\hat{t}_{\mathrm{s}}$ compared to $\hat{t}_{\mathrm{m}}$ was observed in nine populations; however, the difference was only significant in three: MI-T7 $\left(\hat{t}_{\mathrm{m}}-\hat{t}_{\mathrm{s}}=0.075 \pm 0.014\right.$ S.E. $)$, EOD3 $(0.034 \pm 0.016)$ and MI-D1 $(0.034 \pm 0.017)$.
Goodness-of-fit tests revealed significant differences between observed progeny genotype frequencies and those expected under the mixed-mating model for 62 per cent of 29 population by locus combinations (Table 2). Outcrossing rate estimation using the mixed-mating 
model is based on several assumptions, including equal survival of selfed and outcrossed zygotes from fertilization to when genotypes are assayed, homogeneity of allele frequencies in the pollen pool, a uniform selfing rate among maternal parents and Mendelian segregation of marker genes. While the last of these assumptions appears to be satisfied by the isozyme loci used here (C. G. Eckert \& S. C. H. Barrett, unpublished data), the first three may be violated to some extent in populations of $D$. verticillatus. Detailed analysis of the observed deviations indicated that while some component was due to heterogeneity in outcrossing rates and pollen allele frequencies among maternal parents, a larger component may be due to the sensitivity of the goodness-of-fit test to uneven allele frequencies (Eckert, 1993). Schoen \& Clegg (1984, 1986) suggested that the distribution of bootstrap estimates may be quite sensitive to violations of underlying assumptions. Hence, examination of the distribution provides some assessment of the aptness of the mixedmating model. For the estimates presented here, bootstrap values for $\hat{t}_{\mathrm{m}}$ were more or less normally distributed and did not exhibit wide variance compared to previously published estimates. Finally, because progeny genotypes were assayed at the seedling stage, inbreeding depression acting during seed maturation and germination may have biased estimates upwards from 5-10 per cent (Eckert, 1993).

Morph-specific estimates. Morph-specific estimates for five trimorphic populations did not reveal large differences among morphs in outcrossing rate (Fig. 1). There was a trend towards reduced outcrossing by the $\mathrm{M}$ morph in three of five populations. Moreover, the overall effect of morph assessed by pairwise comparison of average bootstrap estimates indicated a higher outcrossing rate in the $\mathrm{S}$ morph (average $\left.\hat{t}_{\mathrm{m}}=0.81 \pm 0.03\right)$ than the M morph $(0.62 \pm 0.04)$, with the $\mathrm{L}$ morph $(0.71 \pm 0.04)$ intermediate. The proportion of pairwise differences lying below zero was 0.05 for $\left(\hat{t}_{\mathrm{L}+k}-\hat{t}_{\mathrm{M}+k}\right), 0.03$ for $\left(\hat{t}_{\mathrm{S}+k}-\hat{t}_{\mathrm{L}+k}\right)$ and 0.00 for $\left(\hat{t}_{\mathrm{S}+k}-\hat{t}_{\mathrm{M}+k}\right)$. With an experimentwise type-I error rate of 5 per cent $\left(\alpha_{\mathrm{EW}}=0.05\right)$, only the last of the three contrasts is significant $\left(\alpha_{\mathrm{PC}}=0.017\right)$. In the single dimorphic population including the $\mathrm{L}$ and $\mathrm{M}$ morphs (MI-D1), estimates were higher for the L morph $(0.67 \pm 0.11)$ than the $M$ morph $(0.62 \pm 0.10)$ but the difference was not significant. The absence of the $M$ morph from the remaining dimorphic populations was not associated with higher population-level outcrossing rates than were observed in trimorphic populations $\left[\hat{t}_{\mathrm{m}}\right.$ : trimorphic $=0.72 \pm 0.02 ;$ dimorphic $=0.73 \pm 0.04$; proportion of $\left(\hat{t}_{\mathrm{Di}+k}-\hat{t}_{\mathrm{Tri}+k}\right)$ lying below zero $=0.43$ ].

In the four dimorphic populations including the $\mathrm{L}$ and $\mathrm{S}$ morphs, there was no difference in outcrossing rates among morphs, both within populations (Fig. 1) and for all populations combined [average $\hat{t}_{\mathrm{m}}$ : $\mathrm{L}=0.76 \pm 0.04 ; \quad \mathrm{S}=0.75 \pm 0.04 ; \quad$ proportion of $\left(\hat{t}_{\mathrm{L}+k}-\hat{t}_{\mathrm{S}+k}\right)$ lying below zero $\left.=0.45\right]$.

\section{Rates of disassortative mating}

Morph-specific estimates of $d\left(\hat{d}_{L}\right.$ and $\left.\hat{d}_{S}\right)$ incorporating the mean selfing rate of the three dimorphic populations in eastern Ontario (average $\hat{s}=0.29$ ) adjusted for inbreeding depression $\left(\hat{s}_{\text {adj }}=[0.29][0.614]=0.178\right)$ are presented in Table 3. Comparison of observed frequencies of $\mathrm{L}$ progeny with those expected under a mixture of self-fertilization and either random or disassortative mating revealed significant departures from disassortative mating for the $\mathrm{L}$ morph in all populations. Proportions did not, however, deviate significantly from those expected under mixed selfing and random mating. For $\mathrm{S}$ morph parents, proportions showed a significant deviation from expectation in only one case. However, this exception (EO-D3) involved a higher frequency of $L$ offspring than expected under any mating model (i.e. $L_{S}>0.5$ ) given Mendelian segregation of the style morph alleles.

EO-T3 EO-T6 EO-T11 MI-T3· MI-T7

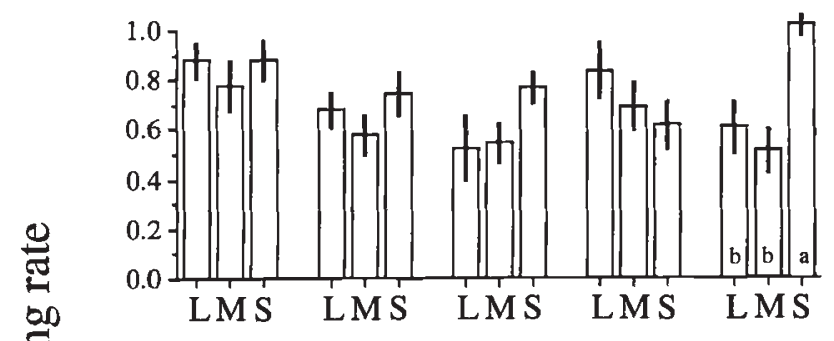

告

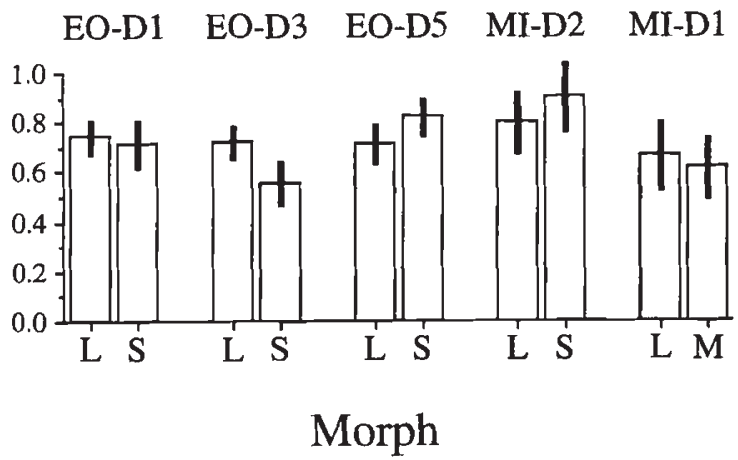

Fig. 1 Morph-specific estimates of the outcrossing rate for 10 populations of tristylous Decodon verticillatus. Error bars are 1 S.E. based on 1000 bootstrap samples per estimate.

Significant pairwise comparisons among morphs in one population are shown by letters at the base of the bars; those not sharing a letter are significantly different. 
Estimates of $d$ based on these proportions ranged from $-0.56\left(\hat{d}_{L}\right.$ in EO-D2) to $+2.54\left(\hat{d}_{S}\right.$ in EO-D3 $)$ and averaged 0.31 (if $\hat{d}_{S}$ in EO-D3 is omitted). They were generally higher for the $\mathrm{S}$ morph (average $\hat{d}_{S}=0.56$, again if $d_{S}$ in EO-D3 is left out) than the $\mathrm{L}$ morph (average $\hat{d}_{L}=0.06$ ). Confidence intervals derived from 1000 bootstraps supported the results of the goodness-of-fit tests in indicating poor statistical reliability of these estimates. In addition, estimates of $d$ were sensitive to assumptions concerning the frequency of homozygous S parents (Fig. 2). Varying the frequency of homozygous $\mathrm{S}$ parents greatly affected dif-

Table 3 Estimated rates of disassortative mating in four dimorphic populations of Decodon verticillatus. Superscripts on proportions of $\mathrm{L}$ morph progeny and estimates of $d$ indicate significant deviations from either random $(r)$ or disassortative ${ }^{(d)}$ mating

Population

\begin{tabular}{|c|c|c|c|c|}
\hline Estimate of & EO-D1 & $\mathrm{EO}-\mathrm{D} 2$ & EO-D3 & EO-T 1 \\
\hline \multicolumn{5}{|c|}{ Parental morph frequencies } \\
\hline L morph & 0.370 & 0.260 & 0.510 & 0.646 \\
\hline S morph & 0.630 & 0.740 & 0.490 & 0.354 \\
\hline \multicolumn{5}{|c|}{ Frequency of recessive allele in pollen } \\
\hline$\hat{q}_{p}$ & 0.638 & 0.575 & 0.718 & 0.796 \\
\hline \multicolumn{5}{|c|}{ Frequency of recessive allele in $\mathrm{S}$ morph parents } \\
\hline$\hat{q}_{S}$ & 0.425 & 0.425 & 0.425 & 0.425 \\
\hline \multicolumn{5}{|c|}{ Parents/progeny sampled } \\
\hline $\mathrm{L}$ morph & $43 / 116$ & $15 / 57$ & $21 / 71$ & $32 / 80$ \\
\hline S morph & $36 / 101$ & $20 / 53$ & $22 / 78$ & $36 / 93$ \\
\hline \multicolumn{5}{|c|}{ Proportion L progeny segregated } \\
\hline $\mathbf{L}$ parents $\left(\hat{L}_{L}\right)$ & $0.655^{d}$ & $0.719^{\mathrm{d}}$ & $0.690^{\mathrm{d}}$ & $0.775^{d}$ \\
\hline $\mathrm{S}$ parents $\left(\hat{L}_{S}\right)$ & 0.317 & 0.321 & $0.538^{\mathrm{r}, \mathrm{d}}$ & 0.366 \\
\hline \multicolumn{5}{|l|}{ Estimate of $d$} \\
\hline $\mathrm{L} \operatorname{morph}\left(\hat{d}_{L}\right)$ & $0.269^{d}$ & $-0.562^{d}$ & $0.325^{\mathrm{d}}$ & $0.189^{d}$ \\
\hline $\mathrm{S} \operatorname{morph}\left(\hat{d}_{S}\right)$ & 0.444 & 0.553 & $2.537^{\mathrm{r}, \mathrm{d}}$ & 0.696 \\
\hline
\end{tabular}

ferences in $\hat{d}$ among morphs. For example, if the frequency of homozygotes is 5 per cent rather than the assumed value of 15 per cent, the substantial difference between $\hat{d}_{L}$ and $\hat{d}_{S}$ observed in EO-T 1 disappears.

\section{Siring differences among pollen types}

Comparison of the siring abilities of different pollen types in mixed pollinations revealed significant prepotency of outcross over self pollen. Replicated goodness-of-fit tests indicated that outcross pollen sired between 1.5 times (between-morph illegitimate pollen) and 1.8 times (legitimate pollen) as many progeny as self pollen. Legitimate pollen, on the other hand, did not experience a significant advantage over illegitimate outcross pollen, and there was no difference in siring success of between-morph illegitimate (BMI) pollen compared to within-morph illegitimate (WMI) pollen (Fig. 3, Table 4).

Examining each morph separately suggested that the relative success of pollen types may differ among morphs. There was a significant siring advantage of both types of outcross pollen over self pollen for the $\mathrm{L}$ and $\mathrm{S}$ morphs but not the $\mathrm{M}$ morph. Also, legitimate pollen experienced a significant overall siring advantage compared to illegitimate pollen on $\mathrm{L}$ recipients; however, the same pattern was not observed among $M$ recipients, and the reverse pattern was seen for $\mathrm{S}$ recipients. Categorical analysis of siring differences indicated a significant effect of morph for the self versus legitimate $(\mathrm{LR}=26.0, \quad P<0.001)$ and illegitimate versus legitimate $(\mathrm{LR}=36.0, P<0.001)$ comparisons only (self versus BMI: $\mathrm{LR}=3.4, P=0.186$; WMI versus BMI: $\mathrm{LR}=1.1, \quad P=0.563$ ). Although pollen was applied almost simultaneously to separate halves of recipient stigmas, order of pollen application had significant effects for all comparisons (self versus legitimate: $\mathrm{LR}=6.9, P=0.009$; self versus $\mathrm{BMI}: \mathrm{LR}=53.7$, $P<0.001$; illegitimate versus legitimate: $\mathrm{LR}=6.0$,
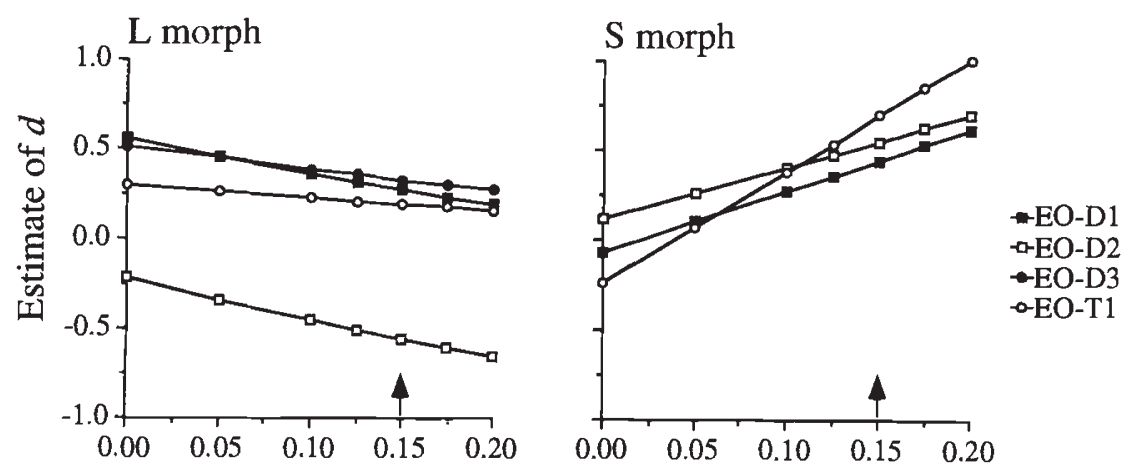

Frequency of homozygotes among S parents

Fig. 2 The effect of assumptions concerning the frequency of homozygous $\mathrm{S}$ morph parents on the estimates of disassortative mating $(d)$ in four dimorphic populations of Decodon verticillatus. The arrow above the abscissa is located at the frequency assumed in the analyses presented in Table 3. The analysis for the S morph in EO-D3 is not shown since estimates of $d$ greatly exceeded unity. 
Fig. 3 Relative siring success of different pollen types following mixeddonor pollinations in Decodon verticillatus. Results are shown for each morph separately and for all morphs pooled. Hatched lines indicate equal siring success. Asterisks above the bars indicate the significance of the pooled deviation from equal siring success in replicated goodness-of-fit tests ('ns' $\left.P>0.05,{ }^{*} P<0.05,{ }^{* * *} P<0.001\right)$. All comparisons used the same six recipient plants per morph. Bars are based on the genotypes of 240 offspring per morph per comparison.
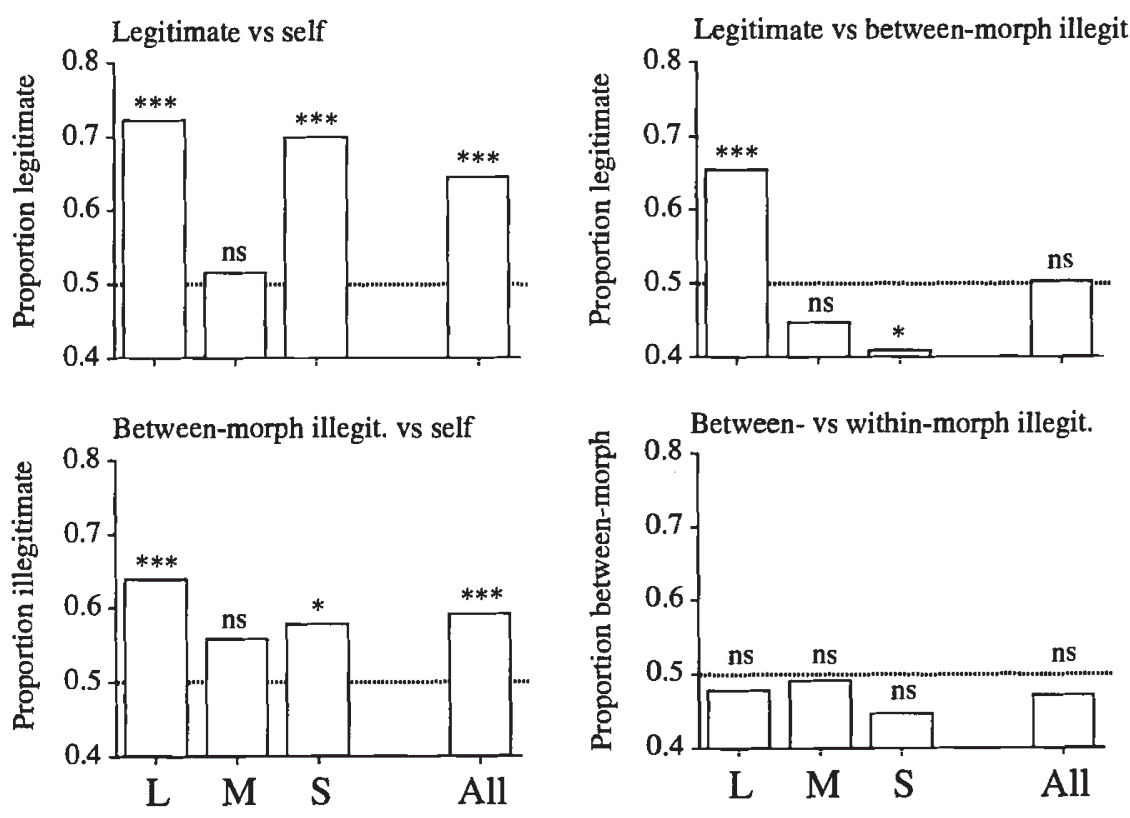

\section{Morph}

Table 4 Siring success of different pollen types after mixed pollination in Decodon verticillatus. The experiment involved four comparisons: (1) self pollen (Self) mixed with legitimate (Legit.) pollen; (2) self with between-morph illegitimate (BMI); (3) legitimate with between-morph illegitimate; and (4) between-morph illegitimate with within-morph illegitimate (WMI). Recipient genotypes are in parentheses. Each value is the proportion of 40 offspring sired by the donor indicated (for comparisons involving two outcross donors, the indicated donor genotype is in parentheses). Significant departures from equal proportions are indicated by asterisks. Proportions not sharing a letter superscript are significantly different as revealed by a homogeneity of replicates test

\begin{tabular}{|c|c|c|c|c|}
\hline Recipient & $\begin{array}{l}\text { Self vs. Legit. } \\
\text { Legit. }\end{array}$ & $\begin{array}{l}\text { Self vs. BMI } \\
\text { BMI }\end{array}$ & $\begin{array}{l}\text { Legit. vs. BMI } \\
\text { Legit. }\end{array}$ & $\begin{array}{l}\text { BMI vs. WMI } \\
\text { BMI }\end{array}$ \\
\hline $\mathrm{L} 1(\operatorname{Id} h \mathrm{FF})$ & a $0.83^{*}$ & ${ }^{\mathrm{a}} 0.88^{*}$ & ${ }^{\mathrm{ab}} 0.53$ (SS) & ${ }^{\mathrm{ab}} 0.40 \quad(\mathrm{FF})$ \\
\hline $\mathrm{L} 2(M d h \mathrm{SS})$ & a $0.73^{*}$ & b $0.30^{*}$ & ${ }^{\mathrm{a}} 0.90^{*}(\mathrm{SS})$ & ab 0.55 (FF) \\
\hline $\mathrm{L} 3(M d h \mathrm{FF})$ & ${ }^{\mathrm{a}} 0.83^{*}$ & ${ }^{\mathrm{a}} 0.83^{*}$ & ${ }^{\mathrm{a}} 0.73 *(\mathrm{SS})$ & ab 0.45 (SS) \\
\hline $\mathrm{L} 4(M d h \mathrm{FF})$ & ${ }^{\mathrm{a}} 0.75^{*}$ & ab 0.58 & ${ }^{\mathrm{a}} 0.85 *(\mathrm{SS})$ & ${ }^{\mathrm{b}} 0.33^{*}(\mathrm{FF})$ \\
\hline $\mathrm{L} 5(M d h \mathrm{SS})$ & b $0.25^{*}$ & ${ }^{\mathrm{b}} 0.55$ & $\mathrm{~b} 0.50(\mathrm{FF})$ & ab 0.48 (SS) \\
\hline L6 (Mdh SS) & a $0.95^{*}$ & ${ }^{\mathrm{a}} 0.70^{*}$ & $\mathrm{~b}^{\mathrm{b}} 0.43(\mathrm{FF})$ & ${ }^{\mathrm{a}} 0.68^{*}(\mathrm{FF})$ \\
\hline $\mathrm{M} 1(M d h \mathrm{FF})$ & ${ }^{\mathrm{a}} 0.73^{*}$ & ab 0.60 & $0.48(\mathrm{FF})$ & ab 0.48 (SS) \\
\hline $\mathrm{M} 2($ Idh SS $)$ & ${ }^{\mathrm{b}} 0.40$ & ${ }^{\mathrm{ab}} 0.65$ & b0.53 (SS) & ab $0.40 \quad(\mathrm{FF})$ \\
\hline M3 (Mdh SS) & ${ }^{\mathrm{a}} 0.70^{*}$ & ${ }^{\mathrm{b}} 0.38$ & ${ }^{\mathrm{b}} 0.18^{*}(\mathrm{SS})$ & ${ }^{\mathrm{ab}} 0.43(\mathrm{FF})$ \\
\hline M4 (Idh SS) & a $0.78^{*}$ & ${ }^{b} 0.42$ & ${ }^{\mathrm{a}} 0.55 \quad(\mathrm{FF})$ & ${ }^{\mathrm{ab}} 0.53(\mathrm{FF})$ \\
\hline $\mathrm{M} 5(M d h \mathrm{FF})$ & ${ }^{\mathrm{b}} 0.10^{* *}$ & $\mathrm{~b}_{0} 0.47$ & $\mathrm{~b} 0.50(\mathrm{FF})$ & ab 0.48 (SS) \\
\hline M6 (Idh SS) & $\mathrm{b} 0.40$ & ${ }^{\mathrm{a}} 0.82^{*}$ & ${ }^{\mathrm{b}} 0.45$ (SS) & ${ }^{\mathrm{ab}} 0.65$ (FF) \\
\hline $\mathrm{S} 1(M d h \mathrm{SS})$ & ${ }^{\mathrm{a}} 0.75^{*}$ & ab 0.65 & ${ }^{\mathrm{b}} 0.35$ (FF) & ab 0.65 (FF) \\
\hline $\mathrm{S} 2(M d h \mathrm{SS})$ & ${ }^{\mathrm{b}} 0.33^{*}$ & ${ }^{\mathrm{b}} 0.45$ & ${ }^{\mathrm{b}} 0.35$ (SS) & ${ }^{\mathrm{ab}} 0.45$ (FF) \\
\hline S3 (Mdh SS) & ${ }^{\mathrm{a}} 0.83^{*}$ & ${ }^{\mathrm{ab}} 0.58$ & ${ }^{\mathrm{b}} 0.33^{*}(\mathrm{FF})$ & ${ }^{\mathrm{ab}} 0.38$ (FF) \\
\hline $\mathrm{S} 4(M d h \mathrm{SS})$ & ${ }^{\mathrm{a}} 0.90^{*}$ & ${ }^{\mathrm{b}} 0.40$ & a 0.60 (SS) & ${ }^{\mathrm{ab}} 0.55 \quad(\mathrm{FF})$ \\
\hline S5 ( $M d h \mathrm{SS})$ & ${ }^{\mathrm{a}} 0.63$ & ${ }^{\mathrm{ab}} 0.60$ & ${ }^{\mathrm{a}} 0.58$ (SS) & ${ }^{\mathrm{b}} 0.33^{*}(\mathrm{FF})$ \\
\hline $\mathrm{S} 6(I d h \mathrm{FF})$ & ${ }^{\mathrm{a}} 0.78^{*}$ & ${ }^{\mathrm{a}} 0.80^{*}$ & $\mathrm{~b} 0.25^{*}(\mathrm{SS})$ & ${ }^{\mathrm{b}} 0.33^{*}(\mathrm{FF})$ \\
\hline
\end{tabular}

$\mathrm{F}=$ fast-migrating allele $\mathrm{S}=$ slow-migrating allele. 
$P=0.014$; WMI versus BMI: $\mathrm{LR}=4.7, P=0.031$ ). Finally, significant heterogeneity among recipients was observed for all pollen comparisons (Table 4). Simultaneous homogeneity of replicates tests suggested the same general differences among morphs revealed by the categorical analyses. For example, in the self versus legitimate comparison recipients fell into two homogeneous groups. Those on which legitimate pollen experienced a siring advantage consisted of $5 \mathrm{~L}, 3 \mathrm{M}$ and $5 \mathrm{~S}$ recipients.

Table 5 Seeds per fruit and proportion of seeds germinating in comparisons of relative siring success among different pollen types in Decodon verticillatus. Pollen comparisons are as in Table 4. Each mean is based on 72 fruits and is shown \pm S.E. Analysis of these data is in Table 6. Means not sharing a letter superscript are significantly different

\begin{tabular}{lrr}
\hline Pollen comparison & Seeds/fruit & Germination \\
\hline Self vs. Legit. & ${ }^{\mathrm{b}} 45.6 \pm 1.9$ & ${ }^{\mathrm{b}} 0.61 \pm 0.02$ \\
Self vs. BMI & ${ }^{\mathrm{b}} 45.7 \pm 1.6$ & ${ }^{\mathrm{b}} 0.60 \pm 0.01$ \\
Legit. vs. BMI & ${ }^{\mathrm{a} b} 48.3 \pm 1.7$ & ${ }^{\mathrm{a}} 0.70 \pm 0.01$ \\
BMI vs. WMI & ${ }^{\mathrm{a}} 51.3 \pm 1.6$ & ${ }^{\mathrm{b}} 0.58 \pm 0.02$ \\
\hline
\end{tabular}

There was no correlation between the siring differences observed for different pollen comparisons on the same recipient $\left(r_{p}\right.$ ranged from -0.14 to +0.15$)$. For example, differences observed for the self versus legitimate comparison were uncorrelated with those observed on the same recipient for the self versus illegitimate comparison $\left(r_{p}=0.09\right)$. Finally, there was significant heterogeneity among comparisons in the number of seeds set per fruit as well as in the proportion of seeds germinating (Tables 5 and 6). Both variables were usually lower for comparisons involving self pollen (Table 5).

\section{Discussion}

In plants which lack strong physiological barriers to self-fertilization the mating system is expected to be strongly influenced by the composition of pollen loads captured by stigmas. The relative amounts of self and outcross pollen on stigmas may vary widely with the size, density, patchiness and clonal structure of populations as well as with the abundance and species composition of the local pollinator fauna (e.g. Horovitz \& Harding, 1972; Ellstrand et al., 1978; Handel, 1983, 1985; Schemske \& Horvitz, 1984). Self-compatible

Table 6 Analysis of variation in seed set and germination in an experimental comparison of siring success (SS) using mixed pollen loads in Decodon verticillatus. Means by pollen comparison are in Table 5 . Recipient and all interactions involving recipient were random effects; others were fixed effects. Significance of $F$-tests is shown as: ${ }^{*} P<0.05,{ }^{* *} P<0.01,{ }^{* * *} P<0.001$. For all other effects, $P>0.1$. Effects are abbreviated by their first letter

\begin{tabular}{|c|c|c|c|c|c|}
\hline \multirow[b]{2}{*}{ Source } & \multirow[b]{2}{*}{ d.f. } & \multicolumn{2}{|c|}{ Seeds per fruit } & \multicolumn{2}{|c|}{ Proportion germinated } \\
\hline & & SS & $F \dagger$ & SS & $F \dagger$ \\
\hline Model & 143 & 46775 & $2.6^{* * *}$ & 4.591 & $2.3^{* * * *}$ \\
\hline Morph $\neq$ & 2 & 10530 & $4.2^{*}$ & 0.003 & 0.0 \\
\hline Recipient $[\mathrm{M}]$ & 15 & 18665 & $9.9^{* * *}$ & 2.217 & $15.3 * *$ \\
\hline Comparison & 3 & 1652 & $3.5^{*}$ & 0.626 & $14.9^{* * * *}$ \\
\hline $\mathrm{C} \times \mathrm{M}$ & 6 & 1129 & 1.2 & 0.163 & 1.9 \\
\hline $\mathrm{C} \times \mathrm{R}[\mathrm{M}]$ & 45 & 7086 & 1.3 & 0.631 & 0.9 \\
\hline Order & 1 & 4 & 0.0 & 0.001 & 0.0 \\
\hline $\mathrm{O} \times \mathrm{M}$ & 2 & 139 & 0.8 & 0.009 & 0.4 \\
\hline $\mathrm{O} \times \mathrm{R}[\mathrm{M}]$ & 15 & 1266 & 0.7 & 0.168 & 0.7 \\
\hline $\mathrm{O} \times \mathrm{C}$ & 3 & 334 & 0.9 & 0.019 & 0.4 \\
\hline $\mathrm{O} \times \mathrm{C} \times \mathrm{M}$ & 6 & 588 & 0.8 & 0.056 & 0.6 \\
\hline $\mathrm{O} \times \mathrm{C} \times \mathrm{R}[\mathrm{M}]$ & 45 & 5231 & 0.9 & 0.699 & 1.1 \\
\hline Error & 142 & 17938 & & 1.986 & \\
\hline$R^{2}$ & & 0.72 & & 0.70 & \\
\hline
\end{tabular}

$\dagger F$-tests used $M S_{R|M|}$ for $\mathrm{M} ;\left(M S_{C \times R|M|}+M S_{O \times R[M]}-M S_{O \times C \times R|M|}\right)$ for $\mathrm{R}[\mathrm{M}]$; $M S_{C \times R|M|}$ for $\mathrm{C}$ and $\mathrm{C} \times \mathrm{M} ; M S_{O \times R|M|}$ for $\mathrm{O}$ and $\mathrm{O} \times \mathrm{M} ; M S_{O \times C \times R[M]}$ for $\mathrm{C} \times \mathrm{R}[\mathrm{M}]$, $\mathrm{O} \times \mathrm{C}$ and $\mathrm{O} \times \mathrm{C} \times \mathrm{M}$; and $M S_{\text {Error }}$ for $\mathrm{O} \times \mathrm{C} \times \mathrm{R}[\mathrm{M}]$.

¥Tukey-Kramer multiple comparisons revealed that, for seed set, $\mathrm{S}=\mathrm{M}>\mathrm{L}$. 
clonal species such as $D$. verticillatus which inhabit a range of habitat types would, therefore, be predicted to exhibit substantial mating-system variation. The results of this study, however, suggest that populations of $D$. verticillatus exhibit a fairly restricted range of outcrossing rates. All populations practised a moderate amount of self-fertilization (average $=30$ per cent); however, the variation in outcrossing rates was limited with few significant differences among populations. This result was unexpected given the range of demographical characteristics and habitat types represented by the 10 populations included in this study (Table 1). A resolution to the apparent conflict between expectations based on natural history and quantitative estimates of mating-system parameters is provided by the results of the pollen competition experiment. Mixed donor pollinations revealed a substantial siring advantage to outcross pollen over self pollen, thus providing a mechanism that could account for the maintenance of outcrossing in $D$. verticillatus. Below, we consider the possible mechanisms responsible for the siring advantage of outcross pollen, and also discuss the consequences of the observed mating patterns in $D$. verticillatus for the maintenance of tristyly.

\section{Mechanisms causing post-pollination siring differences}

Post-pollination siring advantages to outcross over self pollen have now been demonstrated in several plant species (Bateman, 1956; Glover \& Barrett, 1986; Bowman, 1987; Griffin et al., 1987; Montalvo, 1992; Cruzan \& Barrett, 1993; Rigney et al., 1993). However, in most cases the mechanisms producing the observed variation in siring success have not been clearly identified (Barrett, 1988; Walsh \& Charlesworth, 1992). Other studies showing differences in germination and tube growth between self and outcross pollen (Cruzan, 1989; Hessig, 1989; Aizen et al., 1990) suggest that siring differences may arise from prezygotic inhibition of selfed pollen tube growth. Since siring differences are usually assessed well after fertilization, however, the possibility remains that these differences result from the death of selfed zygotes due to the expression of genetic load. Post-zygotic effects may occur in $D$. verticillatus since significant inbreeding depression has been demonstrated for most stages in the life-history of this species (Eckert \& Barrett, 1994b). In this study, offspring genotypes were assayed shortly after germination. Consequently, inbreeding depression occurring during seed maturation and germination may have contributed to the observed siring advantage to outcrossed pollen.
Direct comparisons of pollen germination, pollen tube growth and embryo formation are required to demonstrate clearly prezygotic incompatibility. However, inferences concerning the nature of post-pollination mechanisms in $D$. verticillatus can be made on the basis of seed set and germination differences observed among pollen comparisons. The proportion of outcrossed offspring resulting from mixed self and outcross (both legitimate and illegitimate) pollinations was, on average, 62 per cent, which translates into a 1.6-fold advantage to outcross pollen. Seed set and germination were, on average, lower in the comparisons involving self pollen (45.6 seed per fruit and 60.5 per cent germination yielding about 28 seedlings) than comparisons involving only outcross pollen (49.8 seeds per fruit and 63.7 per cent germination yielding about 32 seedlings). If decreases in both variables are entirely due to the death of selfed zygotes, then inbreeding depression alone would result in a 1.3-fold advantage to outcross pollen (i.e. mixed pollinations would yield, on average, 16 outcrossed and 12 selfed seedlings). A similar value is obtained from the results of an inbreeding depression study conducted on plants from the same population (Eckert \& Barrett, 1994b). Inbreeding depression may, therefore, account for half of the siring advantage to outcross pollen. In this case, the remaining difference could be ascribed to prepotency of outcross pollen expressed before fertilization.

Since other heterostylous members of the Lythraceae possess strong self- and intramorph-incompatibility, it is possible that some component of the siring differences among pollen types observed in $D$. verticillatus results from a weakened form of heteromorphic incompatibility. If this were true, legitimate pollen should be favoured over all types of illegitimate pollen including self pollen. Pollen competition studies in distylous Amsinckia grandiflora (Weller \& Ornduff, 1977, 1989), A. douglasiana (Casper et al., 1988) and tristylous Eichhornia paniculata (Cruzan \& Barrett, 1993) have shown strong similarities between observed patterns of siring success and those expected with weak heteromorphic incompatibility. In $D$. verticillatus, however, the results of the siring experiment do not provide convincing evidence for cryptic heteromorphic incompatibility. Legitimate pollen did not experience a significant overall siring advantage compared to illegitimate outcross pollen. In addition, illegitimate pollen enjoyed a siring advantage over self pollen above and beyond that expected from inbreeding depression alone.

Conclusions as to the possible mechanisms underlying the siring differences among pollen types observed in $D$. verticillatus are complicated by the heterogeneity in siring patterns observed among morphs. Strong discrimination against illegitimate out- 
cross pollen was observed in the $\mathrm{L}$ morph but not the other two morphs. Also, prepotency of outcrossed pollen was observed in the $\mathrm{L}$ and $\mathrm{S}$ morphs but not the $\mathrm{M}$ morph. Because of relatively small sample sizes ( $n=6$ plants per morph) as well as significant heterogeneity in siring patterns among plants, further work is required to confirm that the observed morph-specific differences in siring patterns are a general feature of populations. The lack of discrimination in the $\mathrm{M}$ morph is particularly puzzling, since inbreeding depression alone would be expected to result in a 1.3fold advantage to outcross pollen, yet there was no significant heterogeneity among morphs with respect to differences in seed set and germination among pollen comparisons (see the Comparison $\times$ Morph interactions in Table 6).

\section{Mating patterns in self-compatible tristylous populations}

The absence of self- and intramorph-incompatibility in D. verticillatus is associated with substantial departures from disassortative mating, with a third of all offspring produced by self-fertilization. Measures of disassortative mating are difficult to interpret because of the large S.E.s, and because estimates are sensitive to assumptions concerning genotypic frequencies in the $\mathrm{S}$ morph. The estimates do, however, suggest that moderate levels of disassortative mating occur in populations of D. verticillatus. Theoretical studies on the maintenance of tristyly indicate that even small amounts of disassortative mating are important in buffering finite populations against stochastic morph frequency variation (Eckert \& Barrett, 1992). However, the fact that most matings are not disassortative may, in part, explain the common occurrence of non-trimorphic populations in $D$. verticillatus. This conclusion is strengthened by the observation of infrequent morph loss in related Lythrum salicaria, which possesses strong self- and intramorph-incompatibility (Eckert \& Barrett, 1992).

This study provides limited support for the expectation that the $\mathrm{M}$ morph experiences higher levels of selffertilization than the other morphs (Charlesworth, 1979), as differences in outcrossing rates between morphs were small and not observed in all populations. There is some indication that morph-specific differences in post-pollination discrimination may contribute to mating-system differences among morphs; however, a larger component may be due to differences in the intensity of self-pollination resulting from differences among morphs in the relative positions of stigmas and anthers. Detailed studies of pollen flow in tristylous Pontederia cordata revealed that $\mathrm{M}$ stigmas capture four times as much self pollen as $\mathrm{L}$ or $\mathrm{S}$ stigmas
(Barrett \& Glover, 1985). Similar studies are required to determine whether differences in floral morphology among morphs influence levels of self-pollination in $D$. verticillatus.

Although post-pollination mechanisms might be chiefly responsible for maintaining outcrossing in populations of $D$. verticillatus, the lack of wide variation in outcrossing rates among populations and morphs may also be a function of floral polymorphism. The populations examined in this study were either trimorphic or dimorphic. Yet, many populations of $D$. verticillatus, particularly in northern parts of the species' range, consist of a single style morph (Eckert \& Barrett, 1992). Unfortunately, mating-system estimates could not be obtained for these populations due to a lack of allozyme polymorphism. Indeed, most monomorphic populations may represent single clonal genotypes and are, therefore, obligately self-fertilizing (Eckert \& Barrett, 1993a). In those consisting of more than one genotype, mating patterns may be strongly dependent on the floral morph present (see Kohn \& Barrett, 1992). Hence, the effects of differences in floral morphology among morphs may prove to be context-dependent.

\section{Acknowledgements}

We thank William Cole and Fanny Strumas for technical assistance, Marlene Kraml for help in the field, Kermit Ritland for advice on genetic analyses, Philip Brailsford and Karl Wimmi for horticultural help, Deborah Charlesworth and Kermit Ritland for comments on the manuscript, the University of Michigan and Queen's University Biological Stations for logistic support in the field, and the Natural Sciences and Engineering Research Council of Canada (NSERC) for funding this work through an operating grant to SCHB and a postgraduate fellowship to CGE.

\section{References}

Aizen, M. A., SEARCY, K. B. AND MUlCAHY, D. L. 1990. Amongand within-flower comparisons of pollen tube growth following self- and cross-pollinations in Dianthus chinensis (Caryophyllaceae). Am. J. Bot., 77, 671-676.

ALLARD, R. W. 1975. The mating system and microevolution. Genetics, 79, 115-125.

BARRETT, S. C. H. 1988. The evolution, maintenance, and loss of self-incompatibility systems. In: Lovett-Doust, J. and Lovett-Doust, L. (eds) Plant Reproductive Ecology. Patterns and Strategies, pp. 98-125. Oxford University Press, New York.

BARRETT, S. C. H. AND ECKERT, C. G. 1990. Variation and evolution of mating systems in seed plants. In: Kawano, S. (ed.) 
Biological Approaches and Evolutionary Trends in Plants, pp. 229-254. Academic Press, Tokyo, Japan.

BARRETT, S. C. H. AND GLOVER, D. E. 1985 . On the Darwinian hypothesis of the adaptive significance of tristyly. Evolution, 39, 766-774.

BARRETT, S. C. H. AND HUSBAND, B. C. 1990. Variation in outcrossing rates in Eichhornia paniculata: The role of demographic and reproductive factors. Plant Sp. Biol., 5, 41-55.

BARRETT, S. C. H. AND SHORE, J. S. 1987. Variation and evolution of breeding systems in the Turnera ulmifolia L. complex (Turneraceae). Evolution, 41, 340-354.

BARRETT, S. C. H., BROWN, A. H. D. AND SHORE, J. S. 1987. Disassortative mating in tristylous Eichhornia paniculata (Pontederiaceae). Heredity, 58, 49-55.

BARRETT, S. C. H., MORGAN, M. T. AND HUSBAND, B. C. 1989 . The dissolution of a complex genetic polymorphism: the evolution of self-fertilization in tristylous Eichhornia paniculata. Evolution, 43, 1398-1416.

BATEMAN, A. J. 1956. Cryptic self-incompatibility in the wallflower: Cheiranthus cheiri L. Heredity, 10, 257-261.

BAWA, K. S. AND BEACH, J. H. 1981. Evolution of sexual systems in flowering plants. Ann. Missouri Bot. Gard., 68, 254-274.

Bowman, R. N. 1987. Cryptic self-incompatibility and the breeding system of Clarkia unguiculata (Onagraceae). Am. J. Bot., 74, 471-476.

CASPER, B. B., SAYIGH, L. S. AND LEE, S. S. 1988. Demonstration of cryptic incompatibility in distylous Amsinckia douglasiana. Evolution, 42, 248-253.

CHARLESWORTH, B. 1992. Evolutionary rates in partially selffertilizing species. Am. Nat., 140, 126-148.

CHARLESWORTH, D. 1979. The evolution and breakdown of tristyly. Evolution, 33, 486-498.

CHARLESWORTH, D. AND CHARLESWORTH, B. 1987. Inbreeding depression and its evolutionary consequences. Ann. Rev. Ecol. Syst., 18, 237-268.

CLEGG, M. T. 1980. Measuring plant mating systems. Bioscience, 30, 814-818.

CRUZAN, M. B. 1989. Pollen tube attrition in Erythronium grandiflorum. Am. J. Bot., 76, 562-570.

CRUZAN, M. B. AND BARRETT, s. C. H. 1993. Contribution of cryptic incompatibility to the mating system of Eichhornia paniculata (Pontederiaceae). Evolution, 47, 925-935.

DAR win, c. 1877. The Different Forms of Flowers on Plants of the Same Species. John Murray, London.

DE NETTANCOURT, D. 1977. Incompatibility in Angiosperms. Springer-Verlag, Berlin.

ECKERT, C. G. 1993. The Evolutionary Maintenance of a Sexual Polymorphism in Clonal Decodon verticillatus (Lythraceae). Ph.D. Thesis, University of Toronto.

ECKERT, C. G. AND BARRETT, s. C. H. 1992. Stochastic loss of style morphs from populations of tristylous Lythrum salicaria and Decodon verticillatus (Lythraceae). Evolution, 46, 1014-1029.

ECKERT, C. G. AND BARRETT, S. C. H. 1993a. Clonal reproduction and patterns of genotypic diversity in Decodon verticillatus (Lythraceae). Am. J. Bot., 80, 1175-1182.
ECKERT, C. G. AND BARRETT, S. C. H. 1993b. The inheritance of tristyly in Decodon verticillatus (Lythraceae). Heredity, 71, 473-480.

ECKERT, C. G. AND BARRETT, S. C. H. 1994a. Tristyly, self-compatibility and floral variation in Decodon verticillatus (Lythraceae). Biol. J. Linn. Soc. (in press).

ECKERT, C. G. AND BARRETT, S. C. H. 1994b. Inbreeding depression in partially self-fertilizing Decodon verticillatus (Lythraceae): Population genetic and experimental analyses. Evolution (in press).

Ellstrand, N. C., TORRES, A. M. AND LEVIN, D. A. 1978. Density and the rate of apparent outcrossing in Helianthus (Asteraceae). Syst. Bot., 3, 403-407.

GANDERS, F. R. 1975. Mating patterns in self-compatible populations of Amsinckia (Boraginaceae). Can. J. Bot., 53, 773-779.

GANDERS, F. R. 1979. The biology of heterostyly. N. Z. J. Bot., 17, 607-635.

GLOVER, D. E. AND BARRETT, S. C. H. 1986. Variation in the mating system of Eichhornia paniculata (Spreng.) Solms. (Pontederiaceae). Evolution, 40, 1122-1131.

GRIFFIN, A. R., MORAN, G. F. AND FRIPP, Y. J. 1987. Preferential outcrossing in Eucalyptus regnans F. Muell. Aust. J. Bot., 35, 465-475.

HANDEL, S. N. 1983. Pollination ecology, plant population structure, and gene flow. In: Real, L. (ed.) Pollination Biology, pp. 163-212. Academic Press, Orlando, FL.

HANDEL, S. N. 1985. The intrusion of clonal growth patterns on plant breeding systems. Am. Nat., 125, 367-384.

HARDING, J., MANKINEN, C. B. AND ELLLIOT, M. 1974. Genetics of Lupinus. VII. Outcrossing autofertility, and variability in natural populations of the Nanus group. Taxon, 23, 729-738.

HESSIG, M. B. 1989. Differential pollen tube success in Geranium caespitosum. Bot. Gaz., 150, 404-410.

HEUCH, 1. 1980. Loss of incompatibility types in finite populations of the heterostylous plant Lythrum salicaria. Hereditas, 92, 53-57.

HOLTSFORD, T. P. AND ELLSTRAND, N. C. 1989. Variation in outcrossing rate and population genetic structure of Clarkia tembloriensis (Onagraceae). Theor. Appl. Genet., 78, 480-488.

HOROVITZ, A. AND HARDING, J. 1972. Genetics of Lupinus. V. Intraspecific variability of reproductive traits in Lupinus nanus. Bot. Gaz., 133, 155-165.

JAIN, S. K. 1976. The evolution of inbreeding in plants. Ann. Rev. Ecol. Syst., 7, 69-95.

KOHN, J. R. AND BARRETT, S. C. H. 1992. Experimental studies on the functional significance of heterostyly. Evolution, 46, 43-55.

LEw1S, D. 1979. Sexual Incompatibility in Plants. Edward Arnold, London.

LLOYD, D. G. 1980. Demographic factors and mating patterns in Angiosperms. In: Solbrig, O. T. (ed.) Demography and Evolution in Plant Populations, pp. 67-88. Blackwell Scientific Publications, Oxford.

MANLY, B. F. J. 1990. Randomization and Monte Carlo Techniques in Biology. Chapman and Hall, New York. 
MARSHALL, D. L. AND FOLSOM, M. w. 1991. Mate choice in plants: an anatomical to population perspective. Ann. Rev. Ecol. Syst., 22, 37-63.

MONTALVO, A. M. 1992. Relative success of self and outcross pollen comparing mixed and single-donor pollinations in Aquilegia caerulea. Evolution, 46, 1181-1198.

ORNDUFF, R. 1993. Intramorph and intermorph compatibility in tristylous populations of Decodon verticillatus (Lythraceae). Bull. Torrey Bot. Club, 120, 19-22.

PIPER, J. G., CHARLESWORTH, B. AND CHARLESWORTH, D. 1984. A high rate of self-fertilization and increased seed fertility of homostyle primroses. Nature, 310, 50-51.

Richards, A. I. 1986. Plant Breeding Systems. George Allen \& Unwin, London.

RICK, C. M., HOLLE, M. AND THORP, R. W. 1978. Rates of crosspollination in Lycopersicon pimpinellifolium: Impact of genetic variation in floral characters. Plant Syst. Evol, 129, 31-44.

RIGNEY, L. P., THOMSON, J., CRUZAN, M. B. AND BRUNET, J. 1993. Differential success of pollen donors in a self-compatible lily. Evolution, 47, 915-924.

RITLAND, K. 1986. Joint maximum likelihood estimation of genetic and mating structure using open-pollinated progenies. Biometrics, 42, 25-43.

RITLAND, K. 1989. Correlated matings in the partial selfer Mimulus guttatus. Evolution, 43, 848-860.

RITLAND, K. 1990a. Inferences about inbreeding depression based on changes of the inbreeding coefficient. Evolution, 44, 1230-1241.

RITLAND, K. 1990b. A series of FORTRAN computer programs for estimating plant mating systems. J. Hered., 81, 235-237.

RITLAND, K. AND GANDERS, F. R. 1987. Covariation of selfing rates with parental gene fixation indices within populations of Mimulus guttatus. Evolution, 41, 760-771.

RITLAND, K. AND JAIN, S. K. 1981. A model for the estimation of outcrossing rate and gene frequencies using $n$ independent loci. Heredity, 47, 35-52.

SAS INSTITUTE INC. 1989. JMP® User's Guide, Version 2.0 Edition. SAs Institute Inc., Cary, North Carolina.

SCHEMSKE, D. W. AND HORVITZ, C. C. 1984. Variation among floral visitors in pollination ability: a precondition for mutalism specialization. Science, 225, 519-521.

SCHOEN, D. J. 1982. The breeding system of Gilia achilleifolia: Variation in floral characteristics and outcrossing rate. Evolution, 36, 352-360.

SCHOEN, D. J. AND CLEGG, M. T. 1984. Estimation of mating system parameters when outcrossing events are correlated. Proc. Natl. Acad. Sci. U.S.A., 81, 5258-5262.

SCHOEN, D. J. AND CLEGG, M. T. 1986. Monte Carlo studies of plant mating system estimation models: the one-pollen parent and mixed mating models. Genetics, 112, 927-945.

SHAW, D. V., KAHLER, A. L. AND ALLARD, R. w. 1981. A multilocus estimator of mating system parameters in plant populations. Proc. Natl. Acad. Sci. U.S.A., 78, 1298-1302.

SIDAK, Z. 1967. Rectangular confidence regions for the means of multivariate normal distributions. J. Am. Stat. Ass., 62 , 626-633.

SOKAL, R. R. AND RoHLF, F. J. 1981. Biometry, 2nd edn. W. H. Freeman and Company, New York.

STEBBINS, G. L. 1957. Self-fertilization and population variability in the higher plants. Am. Nat, 91, 337-354.

WALSH, N. E. AND CHARLESWORTH, D. 1992. Evolutionary interpretations of differences in pollen tube growth rates. Quart. Rev. Biol., 67, 19-37.

WELLER, S. G. AND ORNDUFF, R. 1977. Cryptic self-incompatibility in Amsinckia grandiflora. Evolution, 31, 47-51.

WELLER, S. G. AND ORNDUFF, R. 1989. Incompatibility in Amsinckia grandiflora (Boraginaceae): distribution of callose plugs and pollen tubes following inter- and intramorph crosses. Am. J. Bot., 76, 277-282. 


\section{Appendix 1}

Estimated pollen $(p)$ and ovule $(u)$ allele frequencies in 10 populations of Decodon verticillatus. For diallelic loci, frequencies are given for only one allele ( $\mathrm{S}, \mathrm{M}$ and $\mathrm{F}=$ slow-, medium- and fast-migrating alleles, respectively). S.E.s, derived from 1,000 bootstrap samples, were all about 0.04 . Significant differences between $p$ and $u$ are noted with an asterisk

\begin{tabular}{|c|c|c|c|c|c|c|c|c|c|}
\hline \multirow[b]{2}{*}{ Population } & \multicolumn{3}{|c|}{$M d h$} & \multicolumn{3}{|c|}{$I d h$} & \multicolumn{3}{|c|}{$A c p$} \\
\hline & Allele & $p$ & $u$ & Allele & $p$ & $u$ & Allele & $p$ & $u$ \\
\hline EO-T3 & $S$ & 0.84 & 0.84 & $\mathrm{~S}$ & 0.92 & 0.86 & $\mathrm{~F}$ & 0.52 & 0.54 \\
\hline EO-T6 & $S$ & 0.79 & 0.71 & $S$ & 0.70 & 0.71 & $\mathrm{~F}$ & 0.33 & 0.26 \\
\hline EO-T11 & $S$ & 0.56 & 0.66 & $S$ & 0.92 & 0.91 & $\mathrm{~F}$ & 0.51 & 0.59 \\
\hline MI-T 3 & $S$ & 0.92 & 0.85 & $S$ & 0.80 & 0.82 & $\mathrm{~F}$ & 0.45 & 0.46 \\
\hline MI-T 7 & $S$ & 0.44 & 0.55 & $S$ & 0.38 & 0.54 & $\begin{array}{c}\mathrm{S} \\
\mathrm{M} \\
\mathrm{F}\end{array}$ & $\begin{array}{l}0.21 \\
0.32 \\
0.47\end{array}$ & $\begin{array}{l}0.28 \\
0.22 \\
0.50\end{array}$ \\
\hline EO-D1 & $S$ & 0.50 & 0.51 & $S$ & 0.87 & 0.80 & $\begin{array}{c}\mathrm{S} \\
\mathrm{M} \\
\mathrm{F}\end{array}$ & $\begin{array}{l}0.26 \\
0.04 \\
0.70\end{array}$ & $\begin{array}{l}0.17 \\
0.10 \\
0.74\end{array}$ \\
\hline EO-D3 & $S$ & 0.82 & 0.87 & $S$ & 0.62 & 0.72 & $\begin{array}{c}\mathrm{S} \\
\mathrm{M} \\
\mathrm{F}\end{array}$ & $\begin{array}{l}0.52 \\
0.12 \\
0.36\end{array}$ & $\begin{array}{l}0.38 \\
0.30 \\
0.32\end{array}$ \\
\hline EO-D5 & S & 0.94 & 0.90 & $\mathrm{~S}$ & 0.80 & 0.75 & $\begin{array}{c}\mathrm{S} \\
\mathrm{M} \\
\mathrm{F}\end{array}$ & $\begin{array}{l}0.10 \\
0.53 \\
0.37\end{array}$ & $\begin{array}{l}0.22 \\
0.56 \\
0.22\end{array}$ \\
\hline MI-D2 & $\mathrm{S}^{*}$ & 0.66 & 0.91 & & - & & $\mathrm{F}^{*}$ & 0.76 & 0.44 \\
\hline MI-D1 & $S$ & 0.91 & 0.83 & $S$ & 0.98 & 0.93 & $\mathrm{~F}$ & 0.65 & 0.65 \\
\hline
\end{tabular}

\section{Appendix 2}

We estimated the disassortative fraction of outcrossed matings using an approach modified from Ganders (1975). When estimates of the selfing rate $(s)$ are available, outcrossed matings can be partitioned into a fraction $r$, which is random with respect to style morph, and a fraction $d$, which is disassortative with respect to style morph (i.e. matings between morphs above and beyond that which should occur in the random component). With estimates of the selfing rate $(s)$ and the frequency of the recessive style morph allele both in the pollen pool $\left(q_{p}\right)$ and among $\mathrm{S}$ parents $\left(q_{S}\right)$, the frequencies of $\mathrm{L}$ progeny from $\mathrm{L}$ morph $\left(L_{L}\right)$ and $\mathrm{S}$ morph parents $\left(L_{S}\right)$ can be written as:

$$
\begin{aligned}
& L_{L}=s(1.0)+(1-s)\left[(1-d) q_{p}+d q_{s}\right] \\
& L_{S}=s\left(0.5 q_{S}\right)+(1-s)\left[(1-d) q_{p} q_{S}+d q_{S}\right]
\end{aligned}
$$

where $s+(1-s)(r+d)=1$. With some rearrangement, the rates of disassortative mating for the $L\left(d_{L}\right)$ and $S$ morphs $\left(d_{S}\right)$ can be expressed as:

$d_{L}=\frac{L_{L}-\left[s+(1-s) q_{p}\right]}{(1-s)\left(q_{S}-q_{p}\right)}$

and

$d_{S}=\frac{L_{S}-\left[0.5 s q_{S}+(1-s) q_{S} q_{p}\right]}{(1-s)\left(1-q_{p}\right) q_{S}}$

When flower or pollen production differs among morphs, estimates of $q_{p}$ should be weighted accordingly. In Decodon verticillatus, however, no such differences occur (Eckert, 1993; Eckert \& Barrett, $1993 \mathrm{c})$ so that weighting is unnecessary. 